\title{
REFLEXIONES PARA UNA EDUCACIÓN DECOLONIAL Y FEMINISTA: UN ASUNTO INAPLAZABLE
}

\author{
REFLECTIONS TOWARDS A DECOLONIAL AND \\ FEMINIST EDUCATION: AN URGENT TOPIC
}

\author{
Mara Karidy Polanco Zuleta* \\ María Elza Eugenia Carrasco Lozano* \\ Raquel Güereca Torres ${ }^{\star \star \star}$
}

RESUMEN: En el presente artículo exponemos una serie de reflexiones para ir pensando y consolidando ideas para una educación decolonial y feminista. Empezamos exponiendo los sesgos de género y raza en las ciencias y la exclusión sociopolítica de las mujeres para reflexionar sobre lo que implican las teorías y epistemologías feministas latinoamericanas y decoloniales. Posteriormente abordamos algunas ideas sobre cómo se construyó la educación que hoy en día reproducimos en la que se legitiman y validan sesgos de raza, clase y género. Finalmente, propuestas para tener en cuenta en una educación decolonial y feminista.

Palabras claves: Educación. Estudios decoloniales. Feminismo decolonial.

RESUMO: Neste artigo, apresentamos uma série de reflexões para pensar e consolidar ideias para uma educação decolonial e feminista. Começamos expondo preconceitos de gênero e raça na ciência e a exclusão sociopolítica das mulheres, para continuar com algumas reflexões sobre o que as teorias e epistemologias feministas decoloniais e latino-americanas implicam. Posteriormente, abordamos algumas ideias sobre como a educação que reproduzimos hoje foi construída em que preconceitos de raça, classe e gênero são legitimados e validados. $E$ terminamos expondo algumas ideias a serem levadas em consideração em uma educação decolonial e feminista.

Palavras-chave: Educação. Estudos decoloniais. Feminismo decolonial.

\footnotetext{
Doutoranda em Educação pela Universidad Autónoma de Tlaxcala (México). Mestre em Educação Ambiental pela Universidade Federal do Rio Grande (FURG). Contato: mkaridy@gmail.com

* Doutora em Desenvolvimento Regional pelo Colegio de Tlaxcala, A.C. Pesquisadora Nacional Nivel I do CONACYT, nas linhas Educação, Violência e Gênero. Pesquisadora da Universidad Autónoma de Tlaxcala (México). Contato: elzacarrascolozano@gmail.com

*** Doutora em Ciências Políticas e Sociaies, com orientação em Sociología. Pesquisadora Nacional Nivel I do CONACYT e pesquisadora asociada da Red Mexicana de Ciencia, Tecnología y Género (Red Mexciteg, Red Temática do CONACYT). Pesquisadora da Universidad Autónoma Metropolitana (México). Contato: guereca77@gmail.com
} 
ABSTRACT: In this article, we present a series of reflections to think and consolidate ideas for a decolonial and feminist education. We begin by exposing gender and race prejudices in science and the socio-political exclusion of women, in order to continue reflectioning on what the decolonial and Latin American feminist theories and epistemologies imply. Subsequently, we approached some ideas about how the education we reproduce today was built in which prejudices of race, class, and gender are legitimized and validated. Finally, we expose proposals to be taken into account in a decolonial and feminist education.

Keywords: Education. Decolonial studies. Decolonial feminism.

\section{SESGOS DE GÉNERO Y RAZA EN LA CIENCIA Y EXCLUSIÓN SOCIOPOLÍTICA DE LAS MUJERES}

Para Walter Mignolo (2007), la modernidad y la colonialidad son dos caras de un misma moneda, sin colonialidad no puede haber modernidad y la primera representa la cara oscura de la segunda. En relación con esto, Enrique Dussel (1992) expone que la modernidad nace con la invasión europea en 1492 y se instaura como proyecto de un mundo moderno colonial, el cual ha sido criticado, radicalizado y deconstruido por diversos movimientos sociales y grupos de estudio, pero también por los diversos feminismos. En este sentido, los feminismos critican el paradigma androcéntrico ${ }^{1}$ de la modernidad que, con sus utopías liberadoras de los oprimidos, sepultaba en el olvido, la ignominia y la exclusión el hacer de las mujeres en la sociedad, al reproducir en sus cuerpos y en sus vidas el autoritarismo y la opresión que con tanto ímpetu denunciaban la Revolución Francesa y otros movimientos sociopolíticos que dieron forma a las sociedades modernas.

Sin embargo, si bien los feminismos iniciales son occidentales, es necesario analizar sus teorías desde otros lugares de existencia geográficos y políticos, es

\footnotetext{
${ }^{1}$ El androcentrismo constituye un mecanismo de exclusión de las mujeres basado en el acto de colocar a los hombres y lo masculino en el centro de la elaboración conceptual, de la investigación y de la presentación de resultados; con ello generaliza la experiencia masculina y la traslada al lugar de lo humano. (Norma Blazquez, 2008; Patricia Castañeda, 2008) Esta sobregeneralización de la experiencia masculina produce un ubis de género, que coloca a lo masculino, y con ello a los hombres, como lo humano y lo racional; mientras que lo femenino, y con ello las mujeres, son relegadas a lo no-humano, no-racional, emotivo, reproductivo; y en el ámbito de la producción de conocimientos.
} 
decir, desde otros cuerpos de mujeres que no sean las mujeres blancas burguesas cis-hetero-sexuales; De aquí que se posicionan otros feminismos del sur, como los feminismos negros, lésbicos, indígenas, latinoamericanos, etc. Entre ellos está la corriente de los feminismos decoloniales; una de sus teóricas, María Lugones (2011), menciona que la crítica hecha por mujeres de color y del tercer mundo al universalismo feminista

se centra en la idea de que la intersección entre raza, clase y sexualidad y género va más allá de las categorías de la modernidad. Si mujer y negro son términos para categorías homogéneas, atómicas, separables, entonces su intersección nos muestra la ausencia de las mujeres negras en vez de su presencia. Así, ver a mujeres no-blancas es ir más allá de la lógica "categorial" (LUGONES, 2011, p. 106).

Es necesario comprender que las diferentes opresiones de raza, clase, género y sexualidad no se aplican de la misma manera para todas las mujeres del mundo, sino que, por el contrario, existen intersecciones que harán que unas puedan tener más privilegios y oportunidad que otras, de aquí que se hable de feminismos en plural, de interseccionalidad y de matriz colonial de género (LUGONES, 2011). Pensando en el campo científico y académico, inicialmente solo algunos hombres podían estudiar, de acuerdo a su nivel económico y prestigio en la sociedad, es decir los burgueses, los demás estarían dedicados a otros tipos de oficio y/o servidumbres. En el caso de las mujeres, solo algunas accedían a estudios "propios de mujeres" y, otras, empobrecidas, estarían dedicadas a la servidumbre, especialmente mujeres negras, de color y racializadas. Es importante resaltar esta segregación histórica de género, clase y raza que influyó en la manera en que se hace ciencia, en la forma de vivir y pensar; así pues, esta forma de imponer un poder sobre el otro o la otra, se acompaña de un componente discursivo. Para Liliana Vargas: 
La dominación colonial implicó un aspecto material, pero también, un aspecto cognitivo, la producción de una forma de vida y de pensar(se), una construcción social particular. Este ámbito discursivo del ejercicio colonial, que involucra la construcción de formas materiales, pero también de pensar y de vivir a partir de las cuales se generará la hegemonía cultural, económica y política de Europa sobre el resto del mundo (VARGAS, 2010, p. 83).

La densidad histórica de esta colonialidad en la ciencia se remonta al surgimiento de la escritura científica basada en las características del caballero noble del siglo XVII que garantizaba la credibilidad del testimonio. Así, el androcentrismo, el clasismo y el racismo son relacionales y se encuentran profundamente imbricados. Son supremacismos que subalternizan el conocimiento y las personas que los producen. La objetividad científica y política, productos de la ciencia moderna, supone un punto cero de observación que descorporiza el conocimiento a través de mecanismos que ocultan a los sujetos y las sujetas que lo produce. Así, el científico no tiene un locus de enunciación, habla desde un lugar invisibilizado. Liliana Vargas propone

[...] una ruptura que resulta central en las discusiones poscoloniales, ella formula una continuidad fundamental entre el proceso colonizador y el surgimiento de la ciencia ilustrada. Punto cero de observación y descorporización del conocimiento parecen entonces, fenómenos estrechamente ligados desde sus lógicas de funcionamiento. Lo cual plantea una visión alternativa, de fuertes diferencias frente a las lecturas tradicionales del fenómeno de la modernidad (VARGAS, 2010, p. 88).

La ciencia moderna e ilustrada, ligada a ese proceso colonizador del que nos habla Liliana Vargas, ha tenido un impacto en la vida sociopolítica de la humanidad. El conjunto de conocimientos sistematizados que la conforman explora diferentes dimensiones de la vida natural y social, y contundentemente legitima un orden social, es decir, donde antes había explicación mitológica y religiosa hoy hay un complejo de explicaciones "contundentes" sobre las relaciones humanas. El conocimiento científico da cuenta de la evolución de la especie y del desarrollo 
humano, a través de dicotomías exhaustivas y excluyentes (MAFFIA, 2005). En este sentido, tenemos una ciencia sexuada, clasista y racista propia del mundo moderno colonial. La dicotomía última que explica la condición de lo humano es: Naturaleza/Cultura, y este par binario ubica lo humano en el ámbito de la transformación simbólica y material de la Naturaleza: la Cultura.

Siguiendo con esta idea, de lo humano y no humano, María Lugones concibe

la jerarquía dicotómica entre lo humano y lo no humano como la dicotomía central de la modernidad colonial. Comenzando con la colonización de las Américas y del Caribe, se impuso una distinción dicotómica, jerárquica entre humano y no humano sobre los colonizados al servicio del hombre occidental. [...] Esta distinción se convirtió en la marca de lo humano y de la civilización. Sólo los civilizados eran hombres y mujeres. Los pueblos indígenas de las Américas y los africanos esclavizados se clasificaban como no humanos en su especie-como animales, incontrolablemente sexuales y salvajes (LUGONES, 2011, p. 106).

Con ello, la Cultura y la Ciencia, que la constituye y la explica, es producto de la ruptura con la animalidad, que es considerada como instintiva frente a la racionalidad de los hombres y mujeres civilizadas, que constituye lo humano y lo científico. En el caso de las mujeres, el conocimiento científico explica, a través de ideologías y estructuras inconscientes, que la evolución de la especie por sí misma es la que asigna un "lugar", un "ubis", a las mujeres; por lo tanto, las relaciones de género "construidas" en relación con el proceso evolutivo deben, por naturaleza, ser así. Este sesgo de género en la ciencia justifica, desde diferentes verdades disciplinares, la forma en que son segregadas las mujeres en diferentes dimensiones de la vida en sociedad, a partir de ciertas características propias de su condición sexuada que la asocian más a lo natural. Así pues, la sexualidad, como construcción cultural del proceso de hominización, está en la Ciencia, y la separación de la Naturaleza es atribuida sólo a los hombres: 


\begin{abstract}
La tesis implícita en esta concepción pone en entredicho la unidad de la especie, ya que las mujeres no evolucionaron con y como los hombres; ellas, definidas a partir de su sexualidad son naturaleza y, en su naturaleza prevalece la animalidad... La centralidad del cuerpo y la sexualidad femeninos son analizados con una visión ecléctica que hace de las mujeres extraños entes naturales que viven en sociedad. (LAGARDE, 1993, p. 195)
\end{abstract}

En este orden de ideas, lo cultural y político son connotaciones transversales que están presentes en todas las sociedades, pues aún con sus peculiaridades han establecidos sistemas de opresión a partir de la diferencia sexual, del género, la raza y la clase, lo cual no solo tiene un impacto en su organización social, sino en las formas de ser y estar en los tiempos y los espacios. Epistemológicamente esto nos coloca en una pedagogía (como administradora de saberes) de lo humano, escindida y altamente discriminatoria.

\title{
¿QUÉ IMPLICA PREGUNTAR POR TEORÍAS Y EPISTEMOLOGÍAS FEMINIS- TAS LATINOAMERICANAS Y DECOLONIALES?
}

Responder esto nos conduce a la reflexión sobre las mujeres como: sujetas de género y sujetas geopolíticas. Chandra Mohanty (2008, p. 119) hace referencia al feminismo de Occidente y lo distingue como un término con el que busca

[...] hacer notar los efectos similares de varias estrategias textuales utilizadas por escritoras que codifican al Otro como no occidental y por tanto (implícitamente) a sí mismas como "occidentales". En este sentido utilizo el término feminismo occidental. Se puede formular un argumento similar en términos de las académicas de clase media urbana en África o Asia que producen estudios académicos acerca de sus hermanas rurales o de clase trabajadora en los que asumen sus culturas de clase media como la norma y codifican las historias y culturas de la clase trabajadora como el Otro.

En base lo anterior, existe una sobregeneralización de la experiencia de las mujeres en las sociedades patriarcales. Pensar en las mujeres en América Latina, nos supone un ejercicio descolonizador del pensamiento y la reflexión científica. Es 
así que María Lugones propone analizar algunas categorías universales que ha producido el feminismo occidental, esta teórica menciona que

\begin{abstract}
Descolonizar el género es necesariamente una tarea práxica. Es entablar una crítica de la opresión de género racializada, colonial y capitalista, heterosexualista, como una transformación vivida de lo social. Como tal ubica a quien teoriza en medio de personas, en una comprensión histórica, subjetiva/intersubjetiva de la relación oprimir $\rightarrow \leftarrow$ resistir en la intersección de sistemas complejos de opresión (LUGONES, 2011, p. 110).
\end{abstract}

Como podemos comprender, el impacto y peso que tienen los sistemas de pensamiento euroccidentales no deja intacta la academia feminista, pues somos producto de las instituciones de educación superior en que se concentra la reproducción de esta colonialidad epistémica. Ante esto, se vuelve preciso incluir la condición geopolítica en la reflexión académica; complejidad que en América Latina se sintetiza en las preguntas de Diana Maffía (2012) al respecto:

- ¿Quién produce conocimiento?

- ¿financiado por quién?

- ¿para beneficio de quién?

- ¿desde la perspectiva de quién?

- ¿en la lengua de quién?

- no sólo en términos de sexo sino también de clase, de etnia, de color, de identidad.

Las preguntas anteriores nos sitúan en espacios-tiempos que han tenido y tienen diferentes sistemas de opresión, tanto económicos como culturales y que se configuran a través de la raza, la clase, el género y la sexualidad. Para descolonizar los feminismos es necesario analizar las categorías que se utilizan desde el feminismo hegemónico occidental, para tener una comprensión de las opresiones de todas las mujeres en este mundo moderno colonial, es decir

La pretensión universalista del feminismo y de categorías como patriarcado y género, empieza a ser cuestionada desde mediados 
de la década de los años 70 , desde posiciones feministas poscoloniales elaboradas por quienes se asumen como "mujeres negras" y "mujeres de color y tercermundistas". Constituyendo a lo largo del tiempo un conjunto de aportaciones dispersas en la geografía, pero situadas geopolíticamente en el tercer mundo o en la periferia del conocimiento y que apuntan a denunciar el carácter eurocéntrico, etnocéntrico y universalizador, el sujeto de los feminismos hegemónicos (MENA, 2017, p. 12).

Así, no podemos reflexionar sobre las mujeres en coordenadas latinoamericanas y pasar por alto las multimilitancias en que se encuentran las mujeres latinoamericanas y que las ubican en tensiones ante: el patriarcado, el mercado global, el colonialismo, la unidimensionalidad de la cultura mediática, el desconocimiento y la invisibilidad de los saberes locales.

Las luchas de las mujeres en América abarcan una gama compleja que, ante el asombro de los ojos occidentales, incluye, por ejemplo, la politización de la maternidad en las dictaduras y la violencia estructural. Emergen así, otras particularidades que no pueden subsumirse en el sujeto de género universal, la mujer. Por ello, develar la heterogeneidad de las mujeres implica un posicionamiento que pregunte por la hibridación y el sincretismo de las mujeres, y que para ello se requiere un tráfico de teorías posibilitadas por la interdisciplina y el diálogo que, desde una perspectiva crítica, se oriente a la transformación de lo que hace el objeto de reflexión: la condición de las mujeres.

Historizar acerca al carácter situado de la experiencia subjetiva, la cual es polisémica, resignificante y paradójica. La linealidad que establece el método empírico-analítico no permite mirar estas contradicciones. De aquí, que los feminismos han construido otras terminologías y ha abierto vetas para el estudio crítico de las mujeres, radicalizando la máxima de la llustración: la Razón. Hace suyo el elemento del paradigma de la modernidad y lo usa en clave feminista. Los feminismos son una cultura que data de más de dos siglos de creación y que se construye en una dialéctica internacional y regional, o en términos acordes con el debate actual, entre lo global y lo local. La cultura feminista en América Latina se 
construye con la resistencia de las mujeres a las opresiones universales a las que son sujetas, pero acompañan luchas y tensiones entre las formas de explotación propias de la región de América Latina y el Caribe. Las mujeres se movilizan en la región desde dos parangones: ante las formas de colonialismo y las formas de opresión particularmente vividas en un cuerpo sexuado.

\section{LA EDUCACIÓN QUE REPRODUCIMOS}

Teniendo en cuenta lo desarrollado anteriormente, la educación actual es heredera de un modelo ilustrado que surge en el siglo XVII en Francia, y que paulatinamente se expande de manera colonialista en el naciente mundo moderno. Llegará a América Latina y el Caribe como parte del proyecto modernizador que dio forma a las naciones independientes del siglo XIX. A lo largo de este apartado describimos la relación entre la ciencia moderna y el modelo educativo laico en las sociedades patriarcales, que da origen al sexismo, clasismo y racismo en los sistemas educativos latino-caribeños ${ }^{2}$.

La educación formal surge con la modernidad euroccidental y anglosajona, con el objetivo de ser el espacio para la formación laica, secular y acorde con los avances científicos que requerían los ciudadanos modernos de la recién nacida democracia liberal. Por lo cual, la escuela se convirtió en la institución socializadora y formadora de futuros ciudadanos y trabajadores de la primera sociedad industrial. Europa Occidental y Estados Unidos formaron sistemas educativos basados en la enseñanza de los avances de la ciencia centrados en el campo de las ciencias naturales, las ciencias sociales y las matemáticas, e hicieron de las Artes y las Humanidades otros saberes que cultivaban el espíritu de los hombres modernos.

Para Ramón Grosfoguel (2016), el canon del pensamiento en las universidades occidentalizadas se basa en la producción de conocimiento de unos

\footnotetext{
${ }^{2}$ En la redacción de este documento no contamos con información profunda y amplia sobre la región del Caribe, lo cual lamentamos. Sin embargo, lo anterior no es razón para no incluir a la región.
} 
cuantos hombres y de unos cuantos países europeos, él expone que desde el origen de las universidades el racismo y el sexismo se encuentra en su estructura epistémica, cuestión que los colonizadores lograron a través de 4 genocidios/epistemicidios a lo largo del siglo XVI, los cuales son: contra el pueblo musulmán y los judíos, contra los pueblos del continente americano y luego los de Asia, contra los africanos y contra las mujeres ${ }^{3}$. Es decir, la educación actual, occidentalizada en Abya Yala, ya sea en escuela o en universidades, fue cimentada en violencias epistémicas, genocidios y feminicidios que fueron parte de la colonización para borrar todos los saberes, cosmovisiones, costumbres y prácticas ancestrales que nuestros pueblos originarios, y afrodescendientes tuvieron. Esta eliminación era necesaria para reproducir y legitimar, de manera colonizadora, un pensamiento colonialista occidental del cual fuéramos dependiente para así validarlo, reproducirlo y legitimarlo.

Este pensamiento eurocéntrico, racista y colonialista también permea los feminismos blancos, liberales y occidentales. Para Bell Hooks (2004), el racismo abunda en el feminismo blanco, reforzando así la supremacía blanca, lo cual imposibilita que muchas mujeres negras y de color se vinculen políticamente a este, atravesando las fronteras étnicas y raciales.

\footnotetext{
Las mujeres blancas que dominan el discurso feminista, que en su mayoría crean y articulan la teoría feminista, muestran poca o ninguna comprensión de la supremacía blanca como política racial, del impacto psicológico de la clase y del estatus político en un estado racista, sexista y capitalista (BIGLIA, 2004, p. 36).
}

Lo anterior nos muestra cómo la raza y la clase se imbrican para generar supremacías, discriminaciones y violencias, incluso dentro de corrientes feministas. De aquí la importancia de ser críticas y críticos sobre las diferentes corrientes feministas que existan. En este sentido, Yuderkys Espinosa Miñoso (2014) expone

\footnotetext{
${ }^{3}$ Para ser precisas, podemos decir que se trató de geno-feminicidios/epistemicidios.
} 
que el pensamiento feminista descolonial se ve relacionado con el feminismo negro, de color y tercermundista que surgió en Estados Unidos y que aporta a la imbricación de la opresión de clase, raza, género y sexualidad; menciona que este feminismo propone recuperar el legado de las mujeres $y$ feministas afrodescendiente e indígenas de Abya Yala.

Esto nos permite analizar que descolonizar y despatriarcalizar la educación es un proceso que debe entender la imbricación que nos menciona Yuderkys y Lugones, y, sobre todo, entrar en un proceso genuino de despertar y apertura a la autocrítica empática sobre cómo y por qué reproducimos discursos y prácticas de violencia racista, patriarcal, colonial y homo-transfóbica, para desligarnos de estas tanto en la teoría como en la práctica. Por ejemplo, Silvia Rivera Cusicanqui (2010, p. 62) nos dice que: "no puede haber un discurso de la descolonización, una teoría de la descolonización, sin una práctica descolonizadora”. Específicamente para ella.

Hay en el colonialismo una función muy peculiar para las palabras: ellas no designan, sino que encubren." Por eso la descolonización no puede ser sólo un pensamiento o una retórica, porque las palabras suelen desentenderse de las prácticas. Se puede hablar contra el racismo mientras éste impregna y orienta, subterráneamente, lo que se hace (CUSICANQUI, 2010, p. 6).

Así pues, es fundamental que docentes, formadoras y formadores de docentes conozcan, estudien e investiguen cómo los estudios y epistemologías decoloniales y feministas potencian una educación que, como Paulo Freire (1967) menciona, sea una fuerza de cambio y de liberación. Si bien la intención de este texto no es entrar en todos los aportes y corrientes decoloniales y feministas existentes, si invitamos a que las, los y les lectores puedan indagar más sobre el tema.

De acuerdo a lo expuesto previamente, es fundamental descolonizar y despatriarcalizar la educación, si bien se estudia el colonialismo, la colonialidad, la modernidad, el patriarcado, el capitalismo, desde algunas disciplinas o campos 
como la historia, las ciencias sociales y políticas, la antropología, entre otras, estos en muchos casos no trascienden las prácticas educativas, y se termina reproduciendo justamente lo que Cristóbal Colon vino hacer, poner todo un continente al servicio de la modernidad/colonial.

En este sentido, tenemos que, en primera medida, preguntarnos cómo las maestras y los maestros de cualquier nivel educativo reproducimos patrones y estereotipos colonialistas, clasistas, racistas y patriarcales, desde nuestros discursos hasta nuestras prácticas; en segunda medida, revisitar de manera colectiva y participativa, las teorías educativas, los modelos curricular, pedagógicos y didácticos, los conocimientos que se enseñan, los autores y las autoras que se estudian; y en tercera medida, establecer políticas públicas educativas que den un sustento legal, pedagógico y administrativo para descolonizar y despatriarcalizar los procesos, los discurso, las prácticas y las instituciones educativas y proponer una educación decolonial y feminista, así como establecer las rutas de atención y de acción a situaciones de violencia por raza, clase, género y sexualidad.

Con lo anterior no queremos decir que no se deba leer o enseñar las ciencias y los conocimientos científicos occidentales, se deben comprender y enseñar para posicionarse, en este caso, desde una educación decolonial y feminista, y sobre todo para enseñar aquello que no fue contado.

Respecto a la formación docente es necesario generar programas de formación docente continua para las, los y les docentes en ejercicio y revisitar los programas de pregrado y posgrado de formación docente, de tal manera que se puedan dar discusiones a nivel epistemológico, pedagógico y político en torno a los estudios decoloniales y feminismos del sur, de tal manera que estos puedan ser transversales a la formación docente y se vean reflejados en los perfiles de las, los y les actuales y nuevos docentes, un formación que les permita a las, los y les educadores comprender que su práctica docente tiene implicaciones políticas (FREIRE, 1967) y que, por lo tanto, es importante hacer consciencia de esto. Es decir, que desde nuestros discursos y prácticas podemos estar legitimando 
cualquier sistema de opresión, cuestión que necesita un proceso de autoreflexividad, personal, genuina y profunda para identificar, aceptar y deconstruir estos sesgos violentos y contribuir a que las nuevas generaciones construyan sus propias reflexiones y deconstruyan sus propias ideas y prácticas machistas, racistas, coloniales y homo-transfóbicas.

Otro aspecto importante es revisitar las lecturas, los, las y les autores que se estudian para saber qué epistemologías se están reproduciendo, cuáles son los sesgos coloniales, raciales y patriarcales que se están legitimando, es decir, analizar si los programas de estudio reproducen estos sesgos y cómo son o no son discutidos en el aula de clases. En este sentido, es necesario trabajar con las, los y les autores para que discutan miradas del Sur Global con planteamientos anticoloniales, antipatriacarles, antirracistas y anticapitalistas. Así pues, como lo plantea Walter Mignolo (2008), hacer una desobediencia epistémica, puesto que no se pueden hacer discusiones de descolonización y despatriarcalización solo en la retórica, sino analizar y reflexionar de manera crítica cómo se lleva a la práctica personal, educativa y docente.

Otro punto para revisitar son las propuestas curriculares, hay que analizar todos los contenidos curriculares, la historia de las ciencias sociales y naturales, de las humanidades, del arte, etc., y rescatar la historia de las, les y los invisibilizados, es decir, rescatar los saberes que producen y producían los pueblos originarios, afrodescendientes y las mujeres, las cosmovisiones, las prácticas y oralidades ancestrales, populares y comunitarias, etc., todo ello para rescatar nuestra historia, cosmovisiones y epistemologías, y desde ahí posicionarnos política y pedagógicamente.

Eliana Ortega (2018), estudiando los programas de educación de Chile, expone que resulta abrumador revisar los programas de educación superior y de formación en educación, pues están al servicio del sistema dominante, expone que categorías como análisis de género no están presentes, lo cual es indispensable para una educación no sexista, categorías que deben de analizar desde los 
diferentes feminismos del sur. Por su parte, en otro estudio, Florencia Rodríguez (2018), realizó un trabajo sobre la formación docente en Argentina, ahí expone que los resultados permitieron evidenciar la pobre presencia y revalorización de la cultura y los saberes locales, expone que el curriculum es marcadamente hegemónico, colonial y está condicionado culturalmente por el discurso científico occidental.

A nivel pedagógico-didáctico, en la práctica docente dentro del aula y fuera del aula, es inaplazable identificar, cuestionar, analizar y deconstruir cómo se reproducen los imaginarios y estereotipos alrededor de lo femenino, lo masculino, lo salvaje y no desarrollado, de lo que debería ser una mujer (blanca, hetero-cissexual, de clase) y un hombre (blanco, hetero-cis-sexual, de clase), incluso de los imaginarios y estereotipos de las personas LGTBI, del binarismo, del sexismo y los estereotipos de género; imaginarios que se reproducen en las imágenes, los chistes, los libros de textos, los ejemplos, las analogías, etc.... que se usan en el aula. Cuestionar y cambiar nuestras prácticas de todo esto es fundamental para trascender una educación androcéntrica, colonial y racista.

Comprendiendo esto, es necesario tener en cuenta una perspectiva crítica decolonial. Catherine Walsh expone que, por ejemplo, la interculturalidad no puede ser flolklórica, ella dice

La significación práctica de este problema, particularmente en educación, puede observarse en una cantidad de esferas incluidas; por ejemplo, la producción de textos escolares, la formación de maestros y los currículos usados en las escuelas. Bajo la sombrilla de la "interculturalidad", los libros de texto que se publican responden a una política de representación que, incorporando muchas imágenes de indígenas y de los pueblos negros, sólo sirven para reforzar estereotipos y procesos coloniales de racialización. En la formación docente, la discusión sobre la interculturalidad se encuentra en general limitada — si existe - al tratamiento antropológico de la tradición folklórica (WALSH, 2007, p. 55). 
En este mismo sentido, pensando en una educación de y para Latinoamérica, debe comprender, estudiar y analizar los planteamientos de los estudios decoloniales y feminismos del sur, dejando de lado o criticando fuertemente los feminismos hegemónicos occidentales para no seguir reproduciendo o adjuntándonos a luchas y movimientos que poco nos representan.

Con esto queremos mencionar que es inaplazable revisitar los conocimientos de todas las disciplinas y seminarios que se imparten en las aulas desde los niveles iniciales hasta los posgrados, en todas las instituciones educativas y de formación. Evidenciar el sexismo, el racismo, el colonialismo y el patriarcado ligado a las epistemologías y cosmovisiones, y la producción de conocimientos de todas las ciencias; las artes y las prácticas son fundamentales para cambiar los discursos que promueven y legitiman sesgos violentos.

Para todo lo anterior, es importante comprender que las Universidades de Latinoamérica juegan un papel importante tanto en la reproducción de las epistemologías coloniales occidentales como de sus resistencias. Para Edgardo Lander, las universidades del sur

\begin{abstract}
Han operado igualmente como correas de transmisión de modos de producción de conocimiento y contenidos de conocimiento coloniales eurocéntricos que han contribuido activa o pasivamente a la deslegitimación 0 destrucción de formas propias de autoconocimiento de las sociedades del Sur desde sus propias tradiciones culturales (LANDER, 2007, p. 173).
\end{abstract}

Consideramos que para que pueda darse un proceso de deconstrucción de esta educación hegemónica, androcéntrica y colonial, debe construirse una política educativa, decolonial y feminista desde el sur Abya Yala, que permita definir líneas estratégicas en torno a la formación docente, la investigación educativa, los currículum, los proyectos educativos y los procesos pedagógicos y didácticos, entre otros. 


\section{A MANERA DE CONCLUSIÓN: EDUCACIÓN DECOLONIAL Y FEMINISTA}

Según lo discutido anteriormente es inaplazable que, desde los posgrados, los pregrados y las instituciones escolares de todo tipo, públicas y privadas, se empiece de manera participativa, crítica y sensible a estudiar, analizar y transversalizar estos estudios. Aquí son fundamentales las políticas públicas. Comprender y conocer de manera crítica el colonialismo, las colonialidades y los procesos descoloniales son no solo interés de las ciencias sociales, sino también para las demás ciencias naturales, humanas, artísticas, deportivas, entre otras. Deberíamos cuestionar nuestras prácticas y discursos para dejar de legitimar, así sea inconscientemente, tantas violencias.

Lo anterior requerirá recuperar las narrativas, las oralidades, los conocimientos, las producciones científicas, las cosmovisiones de la historia borrada de nuestros pueblos de Abya Yala, contar la historia de los vencidos y las vencidas, pero también de las mujeres, de todas las mujeres, afro, negras, prietas, de color, mestizas, bisexuales, homosexuales, transexuales, transgénero, heterosexuales, de todas las edades, de todas las clases, especialmente las racializadas y empobrecidas para, a partir de aquí y con una mirada feminista decolonial, analizar la educación y las prácticas educativas, de tal manera que conlleve un cambio en las prácticas y discursos; es decir, a adoptar un posicionamiento político pedagógico desde el quehacer docente y el quehacer investigativo.

Cada cuerpo docente de cada área escolar o científica podrá generar espacios, talleres, proyectos, programas, estrategias y políticas que permitan identificar, analizar y transformar lo anteriormente expuesto. 


\section{REFERÊNCIAS}

BIGLIA, Bárbara; HOOKS, B. Otras inapropiables: deminismos desde las fronteras. Athenea Digital, v. 13, 2004.

CUSICANQUI, S. Ch'ixinakak utxiwa: una reflexión sobre prácticas y discursos descolonizadores. Buenos Aires: Tinta Limón Ediciones, 2010.

DUSSEL, Enrique. 1492, el encubrimiento del otro: hacia el origen del mito de la modernidad. Madrid: Nueva Utopía, 1992.

ESPINOSA-MIÑOSO, Yuderkys. Una crítica descolonial a la epistemología feminista crítica. El Cotidiano, n. 184, p. 7-12. 2014.

FREIRE, Paulo. Educação como prática da liberdade. São Paulo: Paz a Terra, 1967.

GROSFOGUEL, Ramón. Racismo/sexismo epistémico, universidades occidentalizadas y los cuatro genocidios/epistemicidios del largo siglo XVI. Tabula Rasa, n. 19, p. 31-58, 2013.

LAGARDE, Marcela. Los cautiverios de las mujeres: madresposas, monjas, putas, presas y locas. México: UNAM-PUEG,1993.

LANDER, E. Diálogos a través del Atlántico Sur: saberes hegemónicos y saberes alternativos. Cuadernos de Historia, n. 9, p. 171-182, 2020.

LUGONES, María. Hacia un feminismo descolonial. Buenos Aires: La Manzana de la Discordia, 2011.

MAFFíA, Diana. Alegato desde la periferia. Memorias IX Congreso Iberoamericano de Ciencia, Tecnología y Género. Sevilla, España: OEI, AECID, Junta de Andalucía, CSIC, Universidad de Sevilla, 2012.

MAFFÍA, Diana. Epistemología feminista: por otra inclusión de lo femenino en la ciencia. In: GRAF, Norma; FLORES, Javier. Género, tecnología y ciencia en Iberoamérica. México: UNAM, CEIICH, UNIFEM, Plaza y Valdés, 2005.

MENA, Ana Marcela. Una mirada al feminismo decolonial en América Latina. Madrid: Dykinson, S.L., 2017. 
MIGNOLO, Walter. Desobediência epistêmica: a opção descolonial e o significado de identidade em política. Tradução de Ângela Lopes Norte. Cadernos de Letras da UFF - Dossiê: Literatura, língua e identidade, n. 34, p. 287-324, 2008.

MIGNOLO, Walter. La colonialidad: la cara oculta de la modernidad. Barcelona: Museo de Arte Moderno de Barcelona. 2007.

MOHANTY, Chandra Talpade. Bajo los ojos de Occidente: academia feminista y discursos coloniales. In: NAVAZ, Liliana Suárez; HERNÁNDEZ, Rosalva Aída (orgs.) Descolonizando el feminismo. Madrid: Cátedra, 2011. p. 17-163.

ORTEGA, Eliana. Señas para una educación feminista. Nomadías, n. 25, p. 91-100, 2018.

RODRÍGUEZ, Florencia. Formación docente inicial para la enseñanza de las ciencias un ¿curriculum colonial?. In: Memorias de las Jornadas Nacionales y Congreso Internacional en Enseñanza de la Biología, vol. 1, no. extraordinario, p. 250-256, 2018.

VARGAS-MONROY, Liliana. De testigos modestos y puntos cero de observación: Las incómodas intersecciones entre ciencia y colonialidad. Tabula Rasa, n. 12, p. 73-94, 2010.

WALSH, Catherine. Interculturalidad y colonialidad del poder. Un pensamiento y posicionamiento "otro" desde la diferencia colonial. In: CASTRO-GOMEZ, Santiago. El giro decolonial: reflexiones para una diversidad epistémica más allá del capitalismo global. Bogotá: Siglo del Hombre, 2007. p. 47-62. 